\title{
Veredas
}

Revista de Estudos Linguísticos

https://periodicos.ufj..br/index.php/veredas/index

\section{Goffman na era digital: um estudo da interação no WhatsApp}

\section{Goffman in the digital age: a study of interaction in WhatsApp}

\author{
Maria do Carmo Leite de Oliveira ${ }^{1}$ \\ Pontifícia Universidade Católica do Rio de Janeiro, Brasil
}

Recebido em: 29/04/2021 Aceito em: 25/06/2021

\begin{abstract}
RESUMO
O legado de Goffman foi produzido em uma época caracterizada como pré-digital. Neste trabalho, busco apresentar alguns elementos para pensar a ordem da interação virtual, tomando como referência os conceitos de apresentação do self e rituais cerimoniais, introduzidos por Goffman em sua teoria sobre a interação em copresença. A base deste exercício analítico são observações sobre o uso do WhatsApp na vida social e um conjunto de mensagens instantâneas trocadas, durante a pandemia, entre membros de um círculo privado de relações. Os resultados apontam para a atemporalidade dos insights de Goffman e também para a releitura das noções de circunstante, palco e bastidor, assim como outros modos de expressão do self, dadas as novas possibilidades comunicativas oferecidas pela mediação tecnológica.
\end{abstract}

PALAVRAS-CHAVE:

Ordem interacional. Self e territórios do self. Rituais interpessoais. WhatsApp.

\section{ABSTRACT}

Goffman's legacy was produced in an era characterized as pre-digital. In this paper, I seek to present some elements to think about the order of virtual interaction, taking as reference the notions of self- presentation and ceremonial rituals, introduced by Goffman in his theory on interaction in co-presence. The basis of this analytical exercise are observations on the use of WhatsApp in social life and a set of instant messages exchanged, during the pandemic, between members of a private circle of relationships. The results point to the timelessness of Goffman's insights and also to the rereading of the notions of bystander, stage and backstage, as well other modes of self- presentation given the new communicative possibilities offered by technological mediation.

\section{KEYWORDS:}

Interactional order. Self and territories of the self. Interpersonal rituals. WhatsApp.

\footnotetext{
${ }^{1}$ E-mail: mcleitedeoliveira@ gmail.com|ORCID: 0000-003-3905-8309
} 


\section{Introdução}

Em um estudo sobre Goffman e o uso da comunicação por telefone móvel, Ling (2010) abre o texto contando uma história. Ainda adolescente, ao atravessar o campus da Universidade de Oslo para assistir a uma aula de norueguês, ele se deparou com um grafite, pintado em um dos edifícios, que dizia: "Goffman ergud", ou seja, "Goffman é Deus".

Uma década depois, em um tempo em que celebridades são fabricadas todos os dias, uma pichação dedicada a um sociólogo ainda surpreende. Em se tratando de Goffman, no entanto, a surpresa é relativa. A leitura de seus ensaios continua até hoje a despertar paixões. O que nos toca não é apenas o estilo, mas o fato de sua obra nos colocar diante de um olho mágico por meio do qual vemos os jogos que jogamos, os rituais que praticamos, a ordem moral da sociedade em que vivemos.

Para aqueles que estudam a interação, a admiração por esse autor se deve também ao vanguardismo de sua obra. Como reconhece Giddens (2013, p. 308), Goffman tanto antecipou quanto ajudou a formar o desenvolvimento da Análise da Conversa. O mesmo podemos dizer sobre sua contribuição para o desenvolvimento da Análise da Conversa Multimodal, ao chamar a atenção para a importância das ações corporificadas na interação.

Não são poucos os estudos sobre comunicações mediadas pela tecnologia que buscam em Goffman inspiração. Há duas décadas, Katriel (1999) já demonstrava que o uso do celular levou à mudança de um modelo de interação baseado em um campo situacional para um outro, baseado em um campo relacional, abrangendo interações focadas (Goffman, 1983) e envolvimentos secundários de vários tipos.

Também em 1999, em uma conferência realizada no congresso Discourse, Communication and the Enterprise (DICOEN II), Oliveira (2004) apontava os impactos interacionais promovidos pela integração tecnológica do telefone ao computador, em atendimentos via call center. Em função da alta tecnologia empregada, alterava-se a estrutura de participação em atendimentos de baixo contato, com a introdução de um participante virtual. No papel de animador (GOFFMAN, 2002 [1981]) $)^{2}$, a atendente incluiu na interação a voz do sistema computadorizado. Como um gatekeeper, essa voz passou a controlar a ordem das ações e definir que as únicas informações verdadeiras são aquelas que constam no sistema.

Na obra intitulada The contemporary Goffman, outros estudiosos trazem mais evidências

\footnotetext{
${ }^{2}$ A obra de 2002 é tradução de Beatriz Fontana do original: GOFFMAN, E. Footing. In: . Forms of talk. Philadelphia: University of Pennsylvania Press, 1981.
} 
da atemporalidade dos insights de Goffman quando se pensa a interação tecnologizada. Jenkins (2010), por exemplo, explora a noção de gerenciamento de impressão no contexto digital. Ling (2010), por sua vez, examinando a comunicação móvel, mostra o papel das rotinas e dos rituais interpessoais no desenvolvimento e manutenção da coesão social.

Na mesma linha, proponho examinar como os insights goffmanianos sobre a ordem da interação em situação de copresença se ajustam ao estudo da interação entre usuários de WhatsApp ${ }^{3}$. Para tanto, parto do pressuposto de que cada tecnologia oferece um sistema de possibilidades únicas para a ação e que essas possibilidades promovem e restringem significados e usos (HUTCHBY, 2001).

Atualmente, o WA está vinculado a um tipo de telefone celular integrado a um minicomputador e que dispõe de uma câmera embutida no aparelho. Em função desses recursos e do design do aplicativo, o WA possibilita não apenas chamadas telefônicas, mas muitas outras formas de comunicação com usuários distanciados no tempo e no espaço.

Trata-se, portanto, de um aplicativo que ilustra o empoderamento daquele a quem cabia apenas o papel de consumidor de informação. Como afirma Castells (2009), qualquer pessoa hoje pode gerar mensagens, escolher conteúdos, selecionar receptores e até atingir uma audiência global. Ao permitir o encaminhamento de objetos, muitos deles encontrados na web, o usuário se torna um distribuidor de informações, recontextualizando "notícias" produzidas em diferentes formatos e, muitas vezes, usadas com diferentes objetivos.

Uma razão pessoal também justifica a escolha do WA. Durante a pandemia, de acordo com os gestores desse aplicativo, foi observado um aumento tão significativo de trocas de mensagens instantâneas, que se tornou necessário fazer alterações na própria configuração da plataforma ${ }^{4}$. Como usuária, o que saltou aos meus olhos, nesse período, foi o recebimento de um grande número de WA de encaminhamento de vídeo, sem mensagem de acompanhamento. A prática não era nova, mas, em um contexto de distanciamento físico, estranhava as pessoas compartilharem um objeto sem realizar uma ação verbal.

É, com base em minhas observações sobre o uso do WA na vida social e no levantamento de um conjunto de WA enviados em 2020 por membros do meu círculo íntimo de relações

\footnotetext{
${ }^{3}$ Destepontoemdiante, denominado WA.

${ }^{4}$ Ver JUCÁ, J.; LOPES, L. Estudo aponta que WhatsApp é o aplicativo mais usado durante a pandemia. CNN Brasil, 3 ago. 2020. Disponível em: https://www.cnnbrasil.com.br/tecnologia/2020/08/03/estudo-aponta-que-whatsapp-e-oaplicativo-mais-usado-durante-a-pandemia. Acesso em: jun. 2021.
} 
pessoais, que procuro pensar esse tipo de interação mediada. A literatura sobre trocas comunicativas virtuais tem privilegiado o contexto das redes sociais. Em ambientes como o do Facebook, as relações interpessoais estabelecidas são, segundo Szabla e Blommaert (2017), complexas, de alto grau de incerteza e baixa previsibilidade. Pouco se pesquisa sobre relações pessoais, construías por laços de afeto no ambiente off-line, no convívio em família, no trabalho e em alguma outra comunidade de prática.

O interesse pelo estudo do WA, num contexto privado, ainda não é expressivo e, quando ocorre, o foco são os bate-papos entre os usuários. Wentker (2018), por exemplo, examina como o uso do WA promove a construção linguística da identidade do grupo e do significado social numa comunidade de prática de seis alunos. Contemplar um contexto marcado por outros fatores situacionais pode dar luz a outras dimensões sociais da interação mediada.

O exercício analítico aqui proposto se organiza da seguinte forma. Na primeira seção, faço uma breve apresentação das affordances do aplicativo WA, destacando algumas propriedades que podem afetar o modo de comunicação dos usuários. Na segunda seção, parto da literatura sobre telefonia móvel, para investigar o papel dos rituais cerimoniais no modo como os usuários interagem, seja por mensagens escritas ou em áudio. Na terceira seção, dirijo minha atenção, especificamente, para os WA de encaminhamento de vídeo sem mensagem de acompanhamento. Meu objetivo aqui é o de pensar os modos de visibilidade self de quem fez o encaminhamento. Por fim, apresento um breve resumo das tendências observadas no corpus quanto às regras de conduta e de apresentação do self em WA de encaminhamento de vídeo sem mensagem e sua influência nos entendimentos de definição da situação.

\section{As affordances do WA}

$\mathrm{Na}$ esteira dos impactos da telefonia móvel nas interações sociais, o aplicativo multiplataforma de mensagens instantâneas e chamadas de voz, WA, veio reforçar a onda de uma sociedade da comunicação, que marcou a segunda metade do século XX. De acordo com Breton (1995), foi nesse período que se desenvolveu a crença num homem comunicante que precisa estar conectado a todo momento, estar ligado a todos os acontecimentos por meio da informação. Por oferecer um leque de possibilidades comunicativas, o WA contribuiu para nos tornar cada vez mais comunicantes.

Esse impacto não é devido apenas às propriedades técnicas do aplicativo, mas também ao modo como nos apropriamos dessas propriedades. É, nesse sentido, que busco estabelecer a 
relação entre as affordances do aplicativo e o modo como os participantes interagem.

O conceito de affordances, introduzido por Gibson (1979), foi usado por Hutchby (2001) para se referir às possibilidades que dada tecnologia oferece para a ação. Herring (2007, p. 13) também reconhece que propriedades do hardware e do software podem afetar em algum nível a comunicação, pelo menos em algumas ocorrências.

Com base na tipologia de fatores tecnológicos apresentada por Herring (2007), podemos caracterizar o WA como um sistema assíncrono de comunicação. Essa propriedade não exige que aquele que envia e o que recebe uma mensagem estejam conectados à internet ao mesmo tempo. As mensagens não são perdidas, mas armazenadas, para serem vistas quando o usuário quiser ou puder.

Quem envia um WA pode acompanhar o processo de recepção. O aplicativo informa se a mensagem foi entregue e se foi vista. Uma mensagem vista e não respondida imediatamente pode ser objeto de uma interpretação, muitas vezes, negativa. Para aquele que recebeu o WA uma maneira de se desobrigar de uma resposta imediata é a de desativar, nas configurações do aplicativo, o aviso de mensagem lida.

Outra informação que pode resultar numa expectativa de resposta imediata é aquela que mostra quem está online. Por ser um tipo de transmissão do tipo caractere a caractere, o WA permite aos usuários acompanhar o processo de digitação da mensagem. Quando a digitação de uma sequência de mensagens não é produzida de modo contínuo, isto é, sem pausas significativas entre cada mensagem, a impressão causada é a de que está sendo presumida a disponibilidade para interagir de quem está online.

Outra possibilidade oferecida pelo WA é a de enviar mensagens privadas (para um indivíduo) e de mensagens públicas (para mais de um indivíduo), o que habilita o que Goffman descreveu como a prática do cochicho. Responder a uma mensagem pública por meio de uma mensagem privada implica a mudança de uma interação na região do palco para outra de bastidor. É nas mensagens privadas que se cochicha, que se diz o que não pode ouvido por outros.

Cochichos, nesse ambiente virtual, no entanto, não são tão protegidos como aqueles realizados em situação de copresença. O WA disponibiliza a opção de cópia, de armazenamento e de encaminhamento de uma mensagem. Riscos de perda da face de um participante podem ultrapassar as barreiras do tempo e ser exposta a uma audiência indeterminada e até de massa. Em função do modo como esses recursos são apropriados, é, no mínimo, questionável a afirmação de Giddens (2013, p. 297) de que "uma ameaça sofrida aos olhos daquele que compartilha o 
mesmo espaço físico deixa um participante vulnerável a formas de incômodo psíquico e físico que não existem a distância". A distância, isto é, virtualmente, uma situação de embaraço pode viralizar, estendendo-a um tempo indefinido.

Em termos de canais de comunicação, o WA é rico em possibilidades. Além de chamadas em áudio, podemos fazer chamadas em vídeo. Além de mensagens escritas e em áudio, podemos também encaminhar objetos - visuais e/ou em áudio. O aplicativo dá também a quem foi convocado mais liberdade para decidir em que momento vai tomar ciência das mensagens recebidas. A identificação por foto, nome ou número do telefone tem consequências para essa decisão.

\section{Mobilidades e rituais interpessoais}

Os estudos de Goffman sobre a interação face a face demonstram que a interação social, como a vida social, é uma coisa ordenada. Como afirma Jenkins (2010, p. 257) ${ }^{5}$, "Goffman acreditava que a ordem de interação era substantivamente real, visível e concreta: em algum lugar entre os mundos mentais necessariamente invisíveis das palavras dos indivíduos e os padrões necessariamente abstratos da 'estrutura social'".

Uma evidência disso reside no modo como obrigações morais de conduta se manifestam na ordem da interação via WA. Num estilo goffmaniano, trago aqui não uma citação literária, mas uma matéria jornalística que evidencia a dimensão ritual de uma troca via WA.

A reportagem, publicada no jornal Folha de São Paulo, relata o caso de uma empregada doméstica que recebeu um WA do patrão com a seguinte mensagem: "Bom dia. Você está demitida. Devolva as chaves e o cartão da minha casa. Receberá contato em breve para assinar documentos" 6 .

O caso foi encaminhado à Justiça do Trabalho e, depois de apreciado em duas instâncias, foi assegurada à empregada uma indenização, por danos morais, de três salários mínimos. "Para a Justiça, faltaram consideração, cordialidade e educação" ${ }^{7}$. Não esteve em julgamento se o WA era o meio mais adequado de comunicar uma demissão, mas sim o modo como foi feita a comunicação.

\footnotetext{
5"Goffman believed the interaction order to be substantively real, visible and concrete: somewhere between the necessarily invisible mental worlds of individuals and the necessarily abstract patterns of "social structure".

${ }^{6}$ BRIGATTI, F.; CASTANHO, W. 'Bom dia, você está demitida': Justiça vê abuso em dispensa por WhatsApp e manda pagar indenização. Folha de S.Paulo, 18 jun. 2021.

${ }^{7}$ Ibidem.
} 
Possivelmente, a própria decisão de entrar na Justiça deveu-se à percepção da empregada de que ela não era uma pessoa importante para aquele patrão. As ações verbais realizadas por ele projetam a imagem de um self robotizado que informa a demissão e os procedimentos do desligamento, sem nenhuma expressão de consideração pelo self da empregada. Como afirmou um juiz citado na matéria, "faltou respeito à dignidade do outro" 8 .

Situações em que há uma disparidade de poder evidente entre os participantes não foram, em geral, tratadas por Goffman (GIDDENS, 2013, P.319). Mas a dignidade do self é uma questão central em sua teoria. A face, a imagem pública do self, projetada pela linha de conduta adotada por um participante na interação, é reconhecida por ele como um princípio da ordem da interação.

Qualquer conduta que viole valores e convenções sociais pode comprometer a impressão favorável que se quer causar no outro por meio de nossa linha de conduta e pode ser passível de sanções sociais negativas (GOFFMAN, 1967a). Como toda interação é suscetível a ocorrências de infrações de ordem moral, os participantes procuram, de modo geral, manter o equilíbrio ritual da interação por meio de práticas defensivas e protetoras da face. Uma questão crucial para esse equilíbrio são os cuidados com os territórios do self.

Em Goffman (1971), o termo significa um vasto campo de coisas cujos limites são defendidos por aqueles que reivindicam o direito de posse, de controle e de disposição desses bens. No caso da telefonia, o risco de invasão de um território do self foi acentuado com a introdução dos celulares. Antes, aquele que era chamado se encontrava num território fixo, como a sua casa. Com a telefonia móvel, podemos alcançar qualquer um, em qualquer lugar e a qualquer momento.

Uma das práticas que demonstram cuidado ritual com o terreno do self de um interagente é a de, antes de fazer uma chamada telefônica, enviar uma mensagem de texto checando a disponibilidade de quem foi convocado (“Está podendo falar?").

Quando a resposta é negativa, aquele que negou o acesso recorre também a um ritual de reparação, constituído de ações, como prestação de contas (“Estou numa reunião), expressão de contrariedade pela impossibilidade de atendimento ("infelizmente, não dá") ou promessa de um retorno ("Te ligo daqui a 10 minutos"). Todas essas ações exibem consideração pelos sentimentos daquele a quem foi negado o acesso. 
De acordo com Goffman (1967b), regras de conduta envolvem tanto obrigações morais quanto expectativas de recebimento do mesmo tratamento respeitoso. No exemplo citado, aquele que recusou a convocação sentiu-se obrigado a dar satisfações e/ou a oferecer alternativas. Em situações como essa, são comuns ações responsivas que exibem práticas de reciprocidade de exibição de deferência. Alguns exemplos encontrados no corpus incluem ações que demonstram confiança na impossibilidade de contato ("Claro"; "Tudo bem"; "Sem problema"; "Ok"); e as que demonstram certeza de um futuro retorno ("Depois a gente fala" ou "Me liga quando puder").

O mesmo cuidado ritual foi observado em situações em que o aplicativo informa que o usuário chamado está online. Estar online é muitas vezes interpretado como estar disponível para responder a um chamado. É o que se pode observar num WA composto por uma sequência de três mensagens.

É padrão separar, em diferentes mensagens, ações e ou tópicos da conversa, assim como processar a digitação dessas mensagens de um modo, mais ou menos, contínuo. No entanto, na sequência abaixo, cada mensagem digitada realizava a primeira parte de uma ação e era separada da outra uma pequena, mas significativa pausa.

$\mathrm{Na}$ primeira mensagem, o amigo faz apenas uma saudação ("Oi”) e não inicia imediatamente a digitação de outra mensagem. Após a pausa, inicia o processo de digitação de uma segunda mensagem, checando explicitamente a disponibilidade presumida: "Você pode falar?". Após outra pausa, inicia-se a digitação da terceira, abordando o assunto que motivou o contato.

A distribuição de ações e tópicos em mensagens curtas aponta para outro cuidado ritual com o self do convocado. Apesar de o WA não impor, como o Twitter, restrições quanto ao número de palavras de uma mensagem, o usuário evita produzir mensagens longas. No caso de WA de áudio, a extensão da fala dificulta o processo de manutenção na memória de todos os tópicos que merecem ou pedem uma ação responsiva. O que se observa, nesses casos, é a ocorrência de um ritual de reparação no fecho da mensagem, acrescido ou não de uma explicação ("Desculpa pelo áudio longo").

Até aqui vimos que o envio de uma mensagem texto pode ter uma função reparadora quando checa a disponibilidade do outro para uma conversa telefônica. Em outras situações, porém, esse tipo de WA pode ser tão invasivo quando o toque de um telefone.

Mesmo pessoas que costumam desativar o som de mensagens por WA, frequentemente 
dividem sua atenção com o celular quando estão em um encontro social de copresença, o que pode motivar a interrupção desse encontro preexistente. Um exemplo é contado por Ling (2010). Certa vez, ele e uma colega ocupavam temporariamente um dado território situacional (Goffman, 1971) - a mesa de um restaurante -. No decorrer da conversa, a colega viu no celular uma mensagem da filha. Pensando tratar-se de algo urgente, decidiu fazer uma ligação para saber o que havia. Os efeitos da interrupção foram analisados pelo autor à luz das noções goffmanianas de região de palco e bastidor.

Segundo Ling, a colega se viu obrigada a lidar simultaneamente com dois palcos - o da copresença e o remoto. Em consequência, ela passou a conversar com a filha como se estivesse numa região de palco e não de bastidor, mais apropriada a uma conversa particular. A interrupção tornou frouxa também a interpretação de qual evento comunicativo estava em primeiro ou segundo plano. Para quem estava remotamente situado, poderia parecer que sua interação estava em primeiro plano. No entanto, a interação em copresença era a interação em primeiro plano.

Experiências como a relatada são comuns na nossa vida cotidiana. Mas uma questão que não foi tratada pelo autor são as consequências da interrupção para aquele participante que foi colocado em espera. O que chamo atenção aqui é para a mudança de status de participação desse participante. Ao ser colocado em espera, ele deixa, temporariamente, de ser um participante ratificado da interação em primeiro plano e passa a ser um ouvinte não ratificado em relação à interação em segundo plano.

Ouvintes que acompanham uma conversa de modo não intencional foram identificados por Goffman como "circunstantes", ou seja, alguém que participa de uma situação social "definida como a arena física absoluta na qual as pessoas presentes estão ao alcance visual e auditivo umas das outras" (Goffman, 2002[1981], p.123). No entanto, nos exemplos de Goffman, essa condição de circunstante não envolvia mudança no status de participação. O que se mantém é a obrigação desse ouvinte de agir como se ele não estivesse presente na cena, demonstrando ativamente desatenção civil (Goffman, 1963).

Em algumas situações de interrupção de uma interação em curso, a encenação da desatenção civil pode ser mais desafiadora. Dependendo do território situacional em que se encontram os participantes, há menos focos alternativos para desviar a atenção. Uma estratégia largamente adotada é a de manusear o celular. Quando aquele que foi colocado em espera dirige sua atenção para o celular, ele pode tornar mais convincente a demonstração de que está mais envolvido com o que está vendo do que com aquilo que está ouvindo. 
Os primeiros casos apresentados aqui apontam para situações em que o direito de convocar implica, em algum nível, uma violação de território, o que justificou rituais de deferência. Já no caso de uma interação face a face interrompida, busquei chamar atenção para as consequências interacionais que recaem sobre o comportamento daquele que ficou em espera.

Situações de escuta coagida não envolvem mais apenas conversas ao telefone diante de circunstantes. WA de mensagens em áudio ou em vídeo abertos aos olhos de outros presentes podem ser também situações que causam embaraço, tanto para quem abriu a mensagem quanto para aquele que passou a ter acesso à conversa como um participante não ratificado.

Por mais que se conheça quem enviou o WA, o conteúdo dessas mensagens é imprevisível, o que aumenta o risco de situações embaraçosas. A prática defensiva mais comum para evitar esse embaraço é a de procurar uma área de bastidor - sem circunstantes - para tomar ciência do que foi enviado. Outra prática encontrada no corpus é a de desencorajar mensagens de áudio, incluindo no perfil do usuário a frase: "Sou surda". Outra ainda é a de enviar uma mensagem sugerindo que, em caso de assunto de urgência, seja enviada uma mensagem de texto ("Não posso ouvir. Escreve").

O que chama atenção nesses casos de exposição de uma mensagem a circunstantes é que não é considerado o direito daquele que é chamado involuntariamente a participar de um evento para o qual não foi convidado (Ling, 2010). Não foram observadas também práticas pelas quais circunstantes reivindicassem o direto ao seu território do self. O que se observa em situações como essas são apenas ações corporificadas que demonstram insatisfação.

\section{O self em WA de encaminhamento de vídeo sem mensagem de acompanhamento}

Como afirma Braga (2011, p. 100), “Nas redes sociais, estar é escrever. Não escrever é estar invisível". No entanto, no tipo de WA em exame nesta seção, é recorrente o encaminhamento de um vídeo sem uma mensagem de acompanhamento, seja escrita, seja em áudio.

Esse tipo de WA ampliou a possibilidade de transferência de arquivos, iniciada com o correio eletrônico. Criado para atender à necessidade de agilizar a comunicação entre membros de uma rede, no contexto organizacional, o e-mail inaugurou a prática de encaminhar anexos, com textos, planilhas, dentre outros objetos.

Em contextos institucionais, o encaminhamento de um anexo tem, de modo geral, um objetivo instrumental e raramente é feito sem uma mensagem de acompanhamento. Trata-se de uma prática de caráter cerimonial, que expressa respeito ao território do destinatário, o que pode 
contribuir para a boa vontade do endereçado, especialmente em situações em que esse endereçado não é uma pessoa conhecida no ambiente off-line (Oliveira, 2011). Outra função dessas mensagens de acompanhamento é a de propor uma definição da situação. Geralmente, é ali que é apresentado o enquadre - real ou simulado - da ação que está sendo realizada.

Para Goffman (1996), a definição da situação, em interações em copresença, está relacionada ao modo como um indivíduo à frente de outro projeta, por meio de suas ações verbais e corporificadas, uma imagem pública do self. Essa face projetada não representa a totalidade da pessoa, apenas uma de suas dimensões. Portanto, o self nada mais é do que o efeito de uma performance, podendo variar no curso da interação e de uma interação para outra.

Em WA de encaminhamento de vídeo sem mensagem de texto ou em áudio, a comunicação é de natureza analógica, nos termos de Watzlawick, Beavin e Jackson (1994, p. 57). Referem-se os autores a uma comunicação não verbal que envolve não só os movimentos corporais, mas também qualquer outra manifestação não verbal de que o organismo seja capaz. É, nessa linha, que estendo o conceito de pista comunicacional não verbal a objetos que comunicam metamensagens, isto é, o tipo de relação que está sendo construída com o endereçado.

Nesse tipo de WA, aquele que encaminhou o vídeo não faz declarações denotativas sobre o objeto, mas o objeto projeta aspectos do seu self e o modo como ele vê o endereçado. Um caso que ilustra como o vídeo pode influir na definição da situação foi observado no compartilhamento de uma história de resiliência. Membros de um grupo do WA do qual faço parte receberam esse vídeo acompanhado da seguinte mensagem: "Veja que história linda e emocionante". O enquadre proposto é o de compartilhamento de uma história cujo conteúdo foi considerado como adequado às identidades dos membros do grupo e às dificuldades enfrentadas por todos em tempo de pandemia.

Como lembra Gastaldo (2008, p. 150), a definição da situação "é central para se compreender o modo como as pessoas orientam suas ações na vida cotidiana". O que a mensagem de texto propõe é uma ação de compartilhamento, que não exige uma ação complementar. Em contextos privados, muitos usuários não respondem a esses WA. Apesar de a ação não exigir uma segunda parte, alguns usuários se veem obrigados a realizar ações responsivas que exibam retribuição pela atenção recebida.

Dentre os tipos de ação identificados, estão a expressão de atitudes positivas por meio de um emoticon, ou a expressão de um acordo consensual- sincero ou não - em termos da definição da situação. Situam-se aí ações verbais de concordância com a avaliação feita ("Linda mesmo"); de 
valorização da ação de encaminhamento ("Salvei"); e de aprovação do conteúdo do objeto ("Adorei").

Segundo relato de quem encaminhou esse vídeo, o mesmo WA foi enviado de forma privada para outras pessoas, mas sem a mensagem de acompanhamento. Para surpresa de quem o encaminhou, uma das ações responsivas recebidas foi: “A história é bonita, mas não preciso de sermão".

Mesmo em interações face a face, em que os participantes podem monitorar as ações verbais e não verbais - em função das percepções recíprocas que vão sendo construídas ao longo da interação, divergências de definição de situação são possíveis. O que estou aqui tornando relevante é o fato de uma comunicação analógica ser mais propícia a ambiguidades do que uma comunicação digital (Watzlawick, Beavin e Jackson, 1994). O foco aí é a dimensão relacional da comunicação. A pessoa que recebeu o vídeo interpretou-o como uma comunicação assimétrica, em que alguém se colocava na posição de ensinar ao outro como enfrentar dificuldades. Significados relacionais comunicados de modo analógico estão mais sujeitos, portanto, à subjetividade do outro interagente.

Fissuras relacionais podem também resultar da compatibilidade do conteúdo do vídeo com o que Goffman denomina como a prática de oferta de paz. Por esse acordo, membros de um dado grupo podem se sentir obrigados, em função dos laços de afetos construídos, ou da necessidade de manter o equilíbrio ritual, de selecionar o que pode ser dito e feito com relação a outro interagente. Atualmente, num ambiente de polarização política exacerbada, esse acordo tem sido muitas vezes quebrado.

Durante a pandemia, um objeto que foi ressignificado como questão política foi o tratamento da Covid-19. Para não ferir a coesão do grupo, aqueles que defendiam a ciência e os que a negavam evitaram incluir esse tópico em conversas físicas ou virtuais. As trocas envolvendo o tratamento eram restritas a região de bastidor entre os que estavam alinhados a uma posição ou à outra.

Por isso causou mal-estar, entre os pró-ciência, um WA público de encaminhamento de um vídeo em defesa da cloroquina, sem mensagem de acompanhamento ${ }^{9}$. Sabia-se da identidade política de quem enviou o vídeo, mas a quebra do acordo de oferta de paz provocou reações. Alguns se calaram na região do palco, mas, em mensagens privadas, repudiaram a ação, vista como um desrespeito àqueles que defendem a ciência. Outros reagiram na mesma moeda, 
encaminhando um vídeo que trazia evidências científicas sobre a ineficácia desse tratamento. Outros, em posição mais radical, partiram para o cancelamento de quem encaminhou, bloqueando suas mensagens. Todos definiram a situação como uma provocação, um desrespeito àqueles que defendem posições diferentes.

A visibilidade do self também se manifesta com relação aos papéis discursivos assumidos por quem enviou o WA. Apesar não usar sua máquina de falar/escrever, aquele que encaminhou o vídeo assume o papel de animador (Goffman, 2002[1981]) dando voz a um outro. E, por essa condição, assume também o papel de responsável pelo encaminhamento, ficando sujeito não só a sanções sociais, mas também, em alguns casos, à punição legal.

\section{Conclusão}

Ao tornar explícitas as regras sociais, de natureza moral e prática, que operam implicitamente sobre a ação dos participantes na interação, Goffman deixou-nos um legado que vai além dos limites da copresença e das fronteiras que separam o seu tempo de um tempo presente, marcado pela velocidade das mudanças, não só nos modos de interação, como em todos os âmbitos da vida social.

Apesar de a análise estar limitada a uma pequena amostra de trocas de WA entre pessoas amigas, os resultados são representativos da manutenção dos achados de Goffman sobre a ordem da interação em copresença.

A tendência de tratar o self com cuidado ritual pode ter sido influenciada pelo objetivo primordial das trocas ali realizadas. Diferentemente do que ocorre em grupos de WA de uma comunidade de prática profissional, o que orienta a ação dos usuários, no contexto em exame, não é, em geral, um objetivo instrumental, mas, sim, a manutenção e o fortalecimento das relações interpessoais construídas no ambiente off-line.

Interações entre pessoas amigas costumam ser orientadas por um acordo tácito de renovar continuamente ofertas de paz como meio de manutenção da coesão do grupo. A preocupação com a preservação da face não é, contudo, restrita a essa esfera. Salvo exceções destacadas por Goffman, ela é um princípio da interação, a base para o que entendemos como relações civilizadas. Outro fator que pode também ter influenciado a manutenção dos rituais cerimoniais é a herança compartilhada que temos do uso desses rituais em interações de copresença e, mais recentemente, em interações mediadas pelo celular. Muito do que foi visto como o direito de 
convocar um interagente está relacionado ao cuidado ritual com o território do self daquele que é convocado. O toque de um telefone é uma invasão desse território sem um pedido de licença. $\mathrm{O}$ uso do WA para checar a disponibilidade do convocado evidencia a ativação de um ritual de deferência.

Como já apontado pela literatura sobre telefonia móvel, uma chamada telefônica por celular ressignificou o modo como tratamos o espaço público. Ao oferecer diferentes possibilidades de troca por mensagem de texto, áudio ou vídeo, o WA criou outras oportunidades para a exposição de uma conversa privada diante de participantes não ratificados.

O exercício aqui proposto reafirmou que, nessas situações, o direito ao território desses participantes eventuais não é considerado. Regras de conduta com relação ao respeito a esse direito parecem estar restritas aos manuais de boas maneiras de cada família.

O trabalho também chamou a atenção para um cenário mais específico de escuta coagida trazida pelo WA em situações de interrupção de um encontro social em copresença. A noção de circunstante, em Goffman, não implicava mudança de status de participação daquele que passou a ter acesso a uma conversa. No entanto, no caso que serviu de ilustração para essas situações, observa-se uma revisão do conceito de circunstante. Na interação em primeiro plano, aquele que foi colocado em espera era um participante ratificado. Na interação em segundo plano, no entanto, ele se torna um participante não ratificado da interação em segundo plano. Apesar dessa mudança de status de participação, aquele que foi colocado em espera continua obrigado a demonstrar desatenção civil, contando agora com o celular como um recurso para tornar sua encenação convincente.

Com relação à projeção de self, as trocas de WA de encaminhamento de vídeo sem mensagem de acompanhamento se diferenciam daquelas descritas para interações em situação de copresença. Sem uma mensagem de texto ou de áudio, o único veículo de informação disponibilizado é o próprio vídeo encaminhado. É por meio desse objeto simbólico que quem recebe o WA interpreta a dimensão de self que foi projetada, o que influi no modo como esse participante vai definir a situação.

Em conclusão, o vídeo funciona como uma pista comunicacional analógica que, dada a sua natureza ambígua, pode favorecer tanto uma definição da situação que pode resultar na manutenção ou não do equilíbrio ritual da interação. Transgressores da ordem moral continuam estando sujeitos à punição. 


\section{Referências}

BRAGA, A. Sociabilidades digitais e a reconfiguração das relações sociais. Desigualdade \& Diversidade - Revista de Ciências Sociais da PUC-Rio, Rio de Janeiro, n. 9, p. 95-104, ago./dez. 2011.

BRETON, P. L'utopie de la Communication: le mythe de 'villageplannétaire' Paris: Éditions la Découverte, 1995.

CASTELLS, M. La comunicación en la era digital. Tradução: María Hernández. In: Comunicación y poder. Madrid: Alianza Editorial, 2009. p. 87-190.

GASTALDO, E. Goffman e as relações de poder na vida cotidiana. Revista Brasileira de Ciências Sociais, v. 23, n. 68, p. 149-153, 2008.

GIBSON, J. J. The ecological approach to visual perception. Boston: Houghton Mifflin, 1979.

GIDDENS, A. Goffman, um teórico social sistemático. In: COELHO, M. C. (Org.). Estudos sobre interação: textos escolhidos. Rio de Janeiro: EdUERJ, 2013. p. 285-327.

GOFFMAN, E. Behavior in public places: notes on the social organization of gathering. New York: The Free Press, 1963.

. On face-work. In: . Interaction ritual: essays on face-to-face behavior. New York: Pantheon Books, 1967a. p. 5-45.

. The nature of deference and demeanor. In: . Interaction ritual. New York: Pantheon Books, 1967b. p. 47-96.

. The territories of the self. In: . Relations in public: microstudies of the public order. New York: Basic Books, 1971.

. The interaction order. American Sociological Review, v. 48, n. 1, p. 1-17, 1983.

. A representação do eu na vida cotidiana. 7. ed. Petrópolis, RJ: Vozes,1996.

. Footing. In: RIBEIRO, B. T.; GARCEZ, P. M. (Org.). Sociolinguística interacional. Tradução: Beatriz Fontana. São Paulo: Edições Loyola, 2002. p. 107-148.

HERRING, S. C. A faceted classification scheme for computer-mediated discourse. Language@Internet, v. 4, p. 1-37, 2007. Disponível em: https://internetlinguisticslehman.commons.gc.cuny.edu/files/2014/01/Faceted_Classification_Sche me_for_CMD.pdf. Acesso em: jun. 2021.

HUTCHBY, I. Conversation and technology: from the telephone to the internet. Cambridge: Polity Press, 2001.

JENKINS, R. The $21^{\text {st }}$-century interaction order. In: JACOBSEN, M. H. (Ed.). The contemporary Goffman. New York/London: Routledge, 2010. p. 257-254.

KATRIEL, T. Rethinking the terms of social interaction. Research on Language and Social Interaction, v. 32, n. 1-2, p. 95-101, 1999.

LING, R. The 'unboothed' phone: Goffman and the use of mobile communication. In: JACOBSEN, M. H. (ed.). The contemporary Goffman. New York/London: Routledge, 2010. p. 275-292.

OLIVEIRA, M. do C. L. de. Language, technology and late modernity: a study of interaction in a Call Center. In: GOUVEIA, C. A. M.; SILVESTRE, C.; AZUAGA, L. (Ed.). Discourse, communication and the enterprise: linguistic perspectives. Lisbon: University of Lisbon Centre for English Studies, 2004. 
E-mail messaging in the corporate sector: tensions between technological affordances and rapport management. In: SARANGI, S.; CANDLIN, C. N. (Ed.). Handbook of communication in organisations and professions. Berlin/Boston: De Gruyter Mouton, 2011. p. 387-406.

SZABLA, M.; BLOMMAERT, J. Does context really collapse in social media interaction? Tilburg Papers in Culture Studies, Paper 201, 2017.

WATZLAWICK, P.; BEAVIN,J.H.; JACKSON,D. D. Pragmática da comunicação humana. Tradução Álvaro Cabral. São Paulo: Cultrix, 1994.

WENTKER, M. Code-switching and identity construction in WhatsApp. Evidence from a (digital) community of practice. In: BÖS, B; KLEINKE, S.; MOLLIN, S.; HERNÁNDEZ, N. (ed). The discursive construction of identities on- and offline. Personal- group-collective. Amsterdam/Philadelphia: John Benjamins, 2018. p. 109-132. 